\title{
Rotational Grazing on Rangelands: Synthesis and Recommendations
}

\section{By Joel Brown and Mort Kothmann}

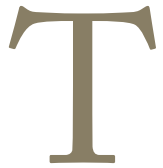

he role of rotational grazing as a management tool on rangelands continues to be controversial. It is unlikely that the papers in this special issue have convinced anyone advocating an extreme pro or con position to change his or her mind. Our intention with this special issue was not to resolve the controversy in one way or another (not that we could!). We did not intend to refute (or even rebut) the findings of the recent paper by Briske et al. ${ }^{1}$ Developing an argument against their findings would require either 1) examining the same literature and coming to a different conclusion or 2) finding peer-reviewed scientific literature that they had overlooked. Although possible, it is not probable that either of these approaches would yield much in the way of useful results.

Likewise, we did not intend to merely confirm the findings of Briske et al. ${ }^{1}$ by inviting a new set of authors to re-interpret the same literature for a different audience. The resolution of this issue requires a much more critical and inquisitive (as well as persistent) approach. Even if there is a lack of experimental evidence supporting the widespread application of rotational grazing as a means to enhance plant or animal production, quite a lot of anecdotal evidence and some eloquent arguments provide a substantial amount of support for the promotion and adoption of some form of rotational grazing to achieve other rangeland management objectives. Thus, our challenge is to figure out how to develop testable hypotheses, perform critical experiments, and transfer the relevant information among a variety of decision makers.

First and foremost among hypotheses that need to be tested is the use of grazing systems for the improved management of livestock. While there remains little evidence that grazing-management decisions beyond proper stocking rate, season of use, distribution, and kind and/or class of animal can substantially affect plant or animal production, there is abundant evidence that rotational grazing in some form can dramatically improve the management and profitability of livestock operations (see the article in this issue by Brunson and Burritt). The challenge here is to avoid the temptation to simply compare already accepted attributes of existing systems (e.g., forage production, species composition, and animal gain) with a host of unknown externalities (e.g., management history, soils, climate, managerial expertise, and inputs) and arrive at the questionable conclusion that one approach is "better" than another (see the article in this issue by Svejcar and Havstad). Added to the relatively straightforward livestock operation questions are the larger issues of financial performance in the multi-year time frame that encompasses wide swings in markets and weather and the integration of these attributes in a decision-support framework (see the article in this issue by Kothmann et al.).

Another very important set of hypotheses that will require rigorous testing is the use of rotational grazing (and grazing management in general) to achieve conservation objectives (see the article in this issue by Budd and Thorpe). Although the relationships among livestock grazing (e.g., stocking rate, season of use, etc.), community-scale plant and soil attributes (e.g., structure, species composition, infiltration, etc.), and fine-scale conservation attributes (e.g., habitat, erosion, runoff, etc.) are relatively well known and quantified, the real environmental issues of the immediate future revolve around how we can organize multi-landowner, multi-site activities to achieve meaningful and measureable conservation objectives at landscape and regional scales (see the article in this issue by Krausmann et al.).

Rangeland researchers, advisors, and practitioners can all be justifiably proud of the progress that we have made in defining, transferring, and implementing the basic principles of good management at the paddock and ranch scale. Our new challenge is to systematically organize these and emerging principles of management in order to simultaneously encompass additional (and similarly important) objectives. Clearly, grazing management and rotational grazing are very complex activities, both in terms of their implementation and in terms of their analysis (see the article in this issue by Kothmann). The experimental designs, metrics, and analytical techniques used in the past are unlikely to offer much insight into these more complex questions. With an 
acknowledgement of our history, current status, and the future demands of grazing management as our guides, we offer these recommendations for improved grazing management research, information transfer, and assessment.

- There is very little to be gained from the continued application of traditional methodologies to evaluate grazing systems. As we said earlier, the relationships between livestock grazing and soil and/or plant attributes at the community scale are well known and predictable. Unless there are new hypotheses or attributes that are clearly beyond our current powers of inference, these experimental approaches are not a wise use of public resources, and their continued application should be questioned. Similarly, an approach that relies on passionate testimonials without meaningful data lacks credibility and will contribute very little to the profession. The emphasis on science-based decision making at all levels of policy development and technical assistance demands that the ethical use of public funds in any form be based on credible, peer-reviewed evidence.

- Research into grazing management in general, and rotational grazing systems in particular, must integrate managerial expertise into well-designed experiments. The endless array of options and adaptive management responses that must be made in order to successfully manage a rangeland-based livestock production system can easily confound a casual observer. By the same token, an experimental approach that externalizes managerial skill is likely to overlook the most important driving variable. Researchers will have to design experiments that quantify managerial inputs as well as environmental variables with an eye toward integrating those inputs into useable decision support. The case-study methodology seems to lend itself well to this type of approach. However, few practicing rangeland scientists have these skills. Clearly, this area of research represents significant opportunities for bringing new scientists and new skills into the profession.

- Although plant performance is relatively predictable across scales, grazing animals behave differently in large, heterogeneous management units than they do in small homogenous units. And those behaviors, if sufficiently well understood, may offer opportunities to predictably enhance animal performance. Clearly, investigations of animal behavior at paddocks and property scales offer some exciting opportunities for research, but experimental approaches must be geared toward developing predictive models that can be integrated into management or the field will be dominated by intellectual curiosities and will offer little to managers beyond interesting discussion.

- While the vast majority of research has focused on animal performance (i.e., gain and reproductive success), the expenditure of public resources demands at least some shift in emphasis toward the potential environmental benefits of livestock grazing on both public and private lands. Experimental design, analysis, and interpretation must be credible at scales at which the responses of interest (e.g., water quality and wildlife populations) emerge, rather than at the most convenient scale to perform research. Gaining credibility with policy makers will also require expanding and integrating new disciplines to better interpret results and to better communicate in a variety of disciplines and with a variety of users.

- Finally, any successful rangeland management research is dependent upon information transfer via a host of activities in order to make an impact. If grazing-management research shifts to a more integrative approach (across space and time), including practitioners and advisors will be not only necessary, but critical. This more inclusive approach should create new pathways for the flow of information in all directions. However, increased opportunities also mean increased attention and resources devoted to interactions among researchers, advisors, and practitioners. Failure to account for this necessity and to devote resources to these important interactions will doom even valuable information to remain in file cabinets or journal papers, rather than being applied to improve land management. Successful interaction among even highly motivated professionals takes time and money. Policy makers and funding organizations must allocate resources accordingly if they expect results.

The implementation of these recommendations would make grazing management research look vastly different than it does in its current format. New skills, new players, new emphases, and new users could have a dramatic effect on our profession and the way we are perceived. Such radical departures over a short time also have the potential to result in a loss of focus. The adoption of these new approaches must be done at the highest level of scientific rigor regardless of the discipline. The basis for improved management will remain, as it always has been, sound scientific evidence.

\section{References}

1. Briske, D. D., J. D. Derner, J. R. Brown, S. D. Fuhlendorf, W. R. Teague, K. M. Havstad, R. L. Gillen, A. J. Ash, and W. D. Willms. 2008. Rotational grazing on rangelands: reconciliation of perception and experimental evidence. Rangeland Ecology \&' Management 61:3-17.

Authors are Rangeland Management Specialist, USDA Natural Resources Conservation Service, Jornada Experimental Range, Las Cruces, NM 88003, USA, joelbrow@nmsu.edu (Brown); and Professor, Dept of Ecosystem Science and Management, Texas AEM University, College Station, TX 77843, USA (Kothmann). 